\title{
INTERAÇÃO E DISCURSO NA UNIVERSIDADE DE CARDIFF: UMA EXPERIÊNCIA MULTICULTURAL
}

\begin{abstract}
Alexandre José Cadilhe é docente da Universidade Castelo Branco (UCB) e Centro Universitário Serra dos Órgãos (UNIFESO), professor contratado do Departamento de Estudos da Linguagem da Universidade do Estado do Rio de Janeiro (UERJ), mestre em Linguistica Aplicada pela UFRJ e doutorando em Estudos da Linguagem pela UFF.

E-mail: alexandre_cadilhe@hotmail.com
\end{abstract}

Durante o mês de junho de 2011, entre os dias 27 e 29, a Universidade de Cardiff, localizada na cidade de mesmo nome, capital do País de Gales, Reino Unido, realizou a sua sexta Summer School: "Analysing Communication in Public and Healthcare Settings". O curso foi sediado no Health Communication Research Centre, organizado pelo seu Diretor, Prof. Sirikant Sarangi. Tal atividade tem como objetivo, através do encontro entre pesquisadores e as orientações dos conferencistas, promover o aprimoramento teórico e metodológico daqueles que se ocupam com pesquisas na área de estudos aplicados da linguagem e práticas de saúde. Apresento, neste relato, algumas reflexões sobre a viagem e a participação neste curso.

O mês de junho é verão e férias nas instituições educacionais na Europa. A chegada à Cardiff antecedeu o dia do curso, e a recepção foi acompanhada por um sol forte porém agradável, convidativo a conhecer a pequena cidade cuja língua divide-se entre o inglês e o galês. O campus universitário localiza-se bem próximo ao centro comercial, acompanhado por prédios históricos (destaque ao Castelo de Cardiff) e uma série de opções culturais, além dos famosos "pubs" britânicos, opção noturna para quem visita a cidade.

A Summer School segue um calendário acadêmico que antecede ao COMET, "Communication, Medicine, and Ethics", tradicional evento marcado pelas exposições e discussões de pesquisas que alinham estudos da linguagem e práticas profissionais em saúde. Tais eventos - COMET e Summer School - parecem ser marcados pela participação internacional: pesquisadores de diversos países da Europa, da Ásia, além dos Estados Unidos e Brasil, continuamente participam destes eventos, sediados a cada ano em uma diferente localidade (a edição de 2009 foi em Boston, MA, EUA, e a de 2012 será na Noruega).

Especificamente sobre a Summer School, o curso foi composto por cerca de 20 participantes, oriundos de diferentes localidades: Escócia, Nova Zelândia, Hong Kong, Noruega, Malásia, Dinamarca, Estados Unidos, Portugal e Brasil, em sua maioria doutorandos ou doutores pesquisadores de Universidades nas áreas de saúde, estudos da linguagem e ciências políticas e sociais. Tal diversidade foi um ponto bastante interessante do encontro, ainda mais pela metodologia adotada pelos organizadores, cuja ordem é a interação: os espaços, momentos e intervalos do curso são todos voltados para a troca, a conversa, a participação. A duração do curso foi de três dias, manhã e 
tarde, incluindo o almoço como momento de conversa no curso. Tal interação foi facilitada por dois elementos: o caderno de programa de curso, o qual apresentou, em suas últimas páginas, um resumo do currículo de cada participante, de modo que cada um pudesse já conhecer os interesses dos participantes; e a própria configuração física das instalações do curso: do café às aulas, incluindo o almoço, todas as salas eram organizadas em círculo, o que facilitava a comunicação. Portanto, em qualquer intervalo das atividades, o padrão interacional era olhar para o lado e conversar!

O curso em si foi organizado em torno de três temáticas: (a) Análise do Discurso, (b) Saúde, Mídia e Discurso e (c) Ética no trabalho em saúde, cada tema trabalhado em um dia da Summer School. As atividades foram organizadas a partir de duas conferências e dois trabalhos em grupo, resultando em seis atividades de cada modalidade ao final dos três dias.

O primeiro dia teve a Análise do Discurso como tema, e foi apresentado pelo Prof. Sirikant Sarangi, diretor do Health Communication Research Centre, da Universidade de Cardiff, linguista e analista do discurso cujas produções recentes tem se voltado para questões de linguagem no trabalho em saúde e em outras práticas profissionais. Foram apresentadas duas conferências sobre análise do discurso: na primeira, o Prof. Sarangi situou uma perspectiva de Análise do Discurso a partir de pesquisas de cunho qualitativo, e os processos de geração de dados, categorização, unidades de análise, evidencias, etc., indicando a diversidade dos estudos da linguagem para tal abordagem. Entre as possibilidades, destaque para a perspectiva dos estudos de linha sócio-interacional de abordagem do discurso, através da "activity analysis", cunhada pelo Prof. Sarangi. A segunda conferência abordou a entrevista como um tipo de atividade produtiva para pontuar configurações interacionais, retóricas, e de posicionamento acerca do tópico em discussão, bem como a responsabilidade do pesquisador em apontar suas "lentes" nos procedimentos analíticos.

As duas conferências do Prof. Sarangi foram acompanhadas por duas atividades em grupo. Na primeira, foram apresentadas duas transcrições de consultas, cujos médicos atenderam a um mesmo paciente. No decorrer da consulta, dois fechamentos: em um, a indicação de um medicamento para a resolução do problema; em outro, a orientação médica de mudança de práticas e outros cuidados. O objetivo de tal análise fora, através dos procedimentos e categorias analíticas, apontar o que, no decorrer de cada interação, poderia ter levado o profissional a indicar o medicamento ou não. Segundo o Prof. Sarangi, tais dados fizeram parte de um estudo mais amplo, solicitado pela organização de saúde pública local, com o intuito de refletir acerca da (alta) dispensa de medicamentos nas práticas médicas. A segunda atividade foi composta por uma entrevista, cuja análise fora para identificar diferentes posicionamentos do enunciador a respeito de sua responsabilização ("accontability") sobre suas práticas de saúde. 
O segundo dia teve como tema a análise de diferentes mídias para compreensão de diferentes temas na área de saúde. As conferências e atividades foram organizadas pelo Prof. Peter Schulz, diretor do Institute of Communication and Health, University of Lugano, cuja produção perpassa os estudos do discurso na perspectiva da retórica e da argumentação, fazendo uso, também, de uma linha quantitativa na abordagem de dados discursivos. A primeira conferência teve como tema as representações da saúde na mídia, e a segunda, a retórica e a argumentação em campanhas de saúde.

As atividades propostas em grupo, por sua vez, tiveram como mote a produção de um roteiro de pesquisa e seleção de objetos da mídia para uma investigação a partir do tema "gripe suína". No caso, deveriam ser apontados os subtemas, objetivos, justificativas, objetos da mídia analisados, além de instrumentais metodológicos para análise.

O último dia do curso tratou do tema da ética no trabalho em saúde, principalmente no que tange à presença do profissional e a comunicação de más notícias. As atividades e conferências foram presididas pelo prof. Michael Branningan, do Departament of Philosophy and Religious Study, College of Saint Rose, Albany, New York. Os temas em discussão versaram sobre as políticas éticas institucionais vigentes, e a credibilidade em tal perspectiva no trabalho profissional em saúde. Outro tema em foco foi a questão da presença do profissional de saúde em seu serviço, no sentido de um embate entre práticas humanizadas e éticas e o uso ou foco nas tecnologias e intervenções biomédicas. O intuito foi refletir sobre as barreiras encontradas no trabalho em saúde que impedem um efetivo encontro entre sujeitos. As atividades em grupo contaram com estudos de caso acerca das escolhas éticas do profissional de saúde diante de problemas, bem como a comunicação em contextos de más notícias.

A experiência na Universidade de Cardiff foi extremamente positiva. Por um lado, pela oportunidade de conhecer o Health Communication Research Centre, instituição de referência no âmbito dos estudos aplicados da linguagem; por outro lado, pela possibilidade de troca de experiências com pesquisadores de outras instituições do mundo que pesquisam práticas sociais em que a linguagem exerce um papel fundamental. Foi interessante observar que, ao lado de todas as diferenças culturais, o que torna o encontro mais rico, a linguagem acadêmica, de certo modo, uniu um grande grupo, quer pelas semelhanças de temas de investigação, quer pelas referências bibliográficas em uso, que geravam verdadeiras identificações de parcerias para trocas de idéias e pesquisas, provocando um reconhecimento mútuo entre os participantes de forma muito significativa, o que parece ser marcante nos eventos organizados pelo Prof. Sarangi.

Após esta experiência, a perspectiva é caminhar nas pesquisas do doutorado e, quem sabe, reencontrar o grupo no COMET de 2012, na Noruega, para que possamos conhecer os resultados de uma série de discussões travadas na Summer School. Aos 
interessados no tema, sintam-se convidados a trocar idéias, informações, referências bibliográficas, entre outros, através do contato indicado. 